\title{
ITIL-based IT service support process reengineering
}

\author{
Raul Valverde*, Raafat George Saade and Malleswara Talla \\ John Molson Business School, Concordia University, Montreal, Canada
}

\begin{abstract}
The Information Technology Infrastructure Library (ITIL) supports best practices, reengineering activities and IT service support processes. ITIL framework only provides recommendations, and companies need to utilize this framework to improve their IT service support processes and establish best practices. This study provides a methodology on how to apply the ITIL framework for evaluating the IT service support processes, its reengineering and alignment to best practices, and subsequent integration into a decision support system framework. A case study approach was used to identify a set of Key Performance Indicators (KPI) which were monitored by a decision support system (DSS) for triggering on-going reengineering of IT service support processes. This paper focuses on the implementation of the ITIL guidelines at the operational level, improvement of the service desk, and incident, problem, change, release, and configuration management. It also presents the implementation of the ITIL guidelines at the tactical level for the improvement of the service level, capacity, IT service continuity, service availability, and security management. We conclude by providing recommendations for future research.
\end{abstract}

Keywords: Information technology infrastructure library, key performance indicators, decision support system

\section{Introduction}

The complexity of Information Technology (IT) applications makes it difficult to effectively assess customer requirements and appropriate service provider capabilities. Customers often have difficulty expressing their service requirements and associated performance needs. Likewise, service providers lack the knowledge to establish efficient IT services for specific customer needs [16].

In order to address these problems, many organizations are adopting the Information Technology Infrastructure Library [2] as a framework to support their primary business processes. In the past, IT support focused on technical issues. Nowadays this focus has shifted to a service-oriented paradigm with emphasis on high quality service provision. The IT Infrastructure Library (ITIL) is a framework of best practices guidelines to manage information technology components

*Corresponding author: Raul Valverde, John Molson Business School, Concordia University, Montreal, Canada. E-mail: rvalverde@jmsb.concordia.ca. and communications in an optimal way. ITIL does not provide a set of rules that must be followed, but guidelines to help organize and arrange the IT organization.

The primary goal of ITIL use is to establish best practices for the continuous improvement of IT service quality between customers and service providers [2]. The ITIL can help organizations achieve the following objectives [2]: better quality control, increased service level, cost reduction, increase efficiency and effectiveness of information supply, unambiguously describing the service in setting up Service Level Agreements (SLAs), and more control over business processes.

The value of ITIL is that it encourages the users to identify, understand and assess their environment (social, organizational, and physical), its associated processes and their interdependencies as they impact all stakeholders. A good example is the clinical information system (CIS) of a bio-medical application, as depicted in Fig. 1 [9]. Figure 1 shows the clinical environment, which includes the workspace tasks and activities; the users, processes, CIS and environment characteristics and their interactions; and the acceptance of the improved IT service from an affective, cognitive, 


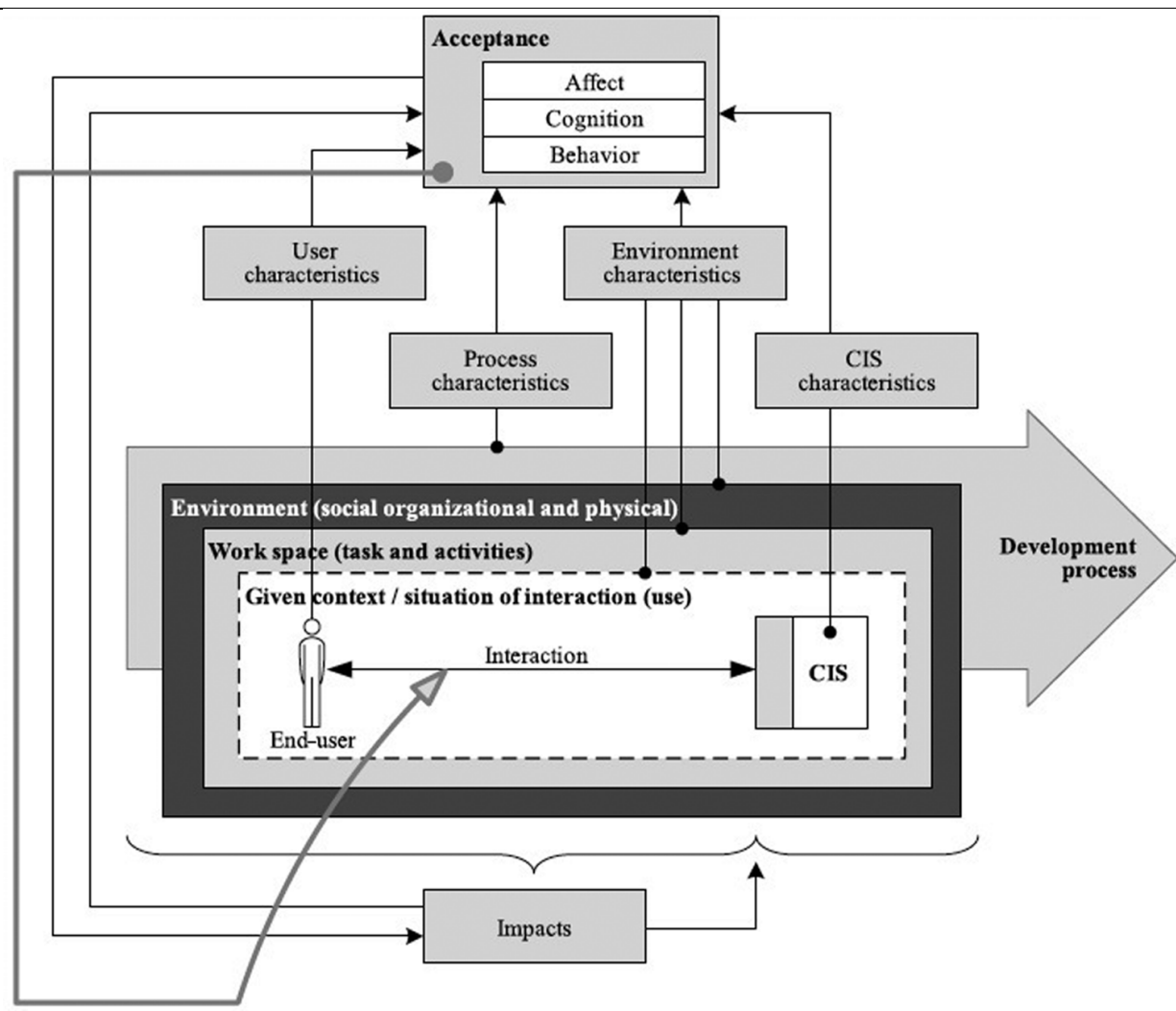

Fig. 1. The information system interaction model [9].

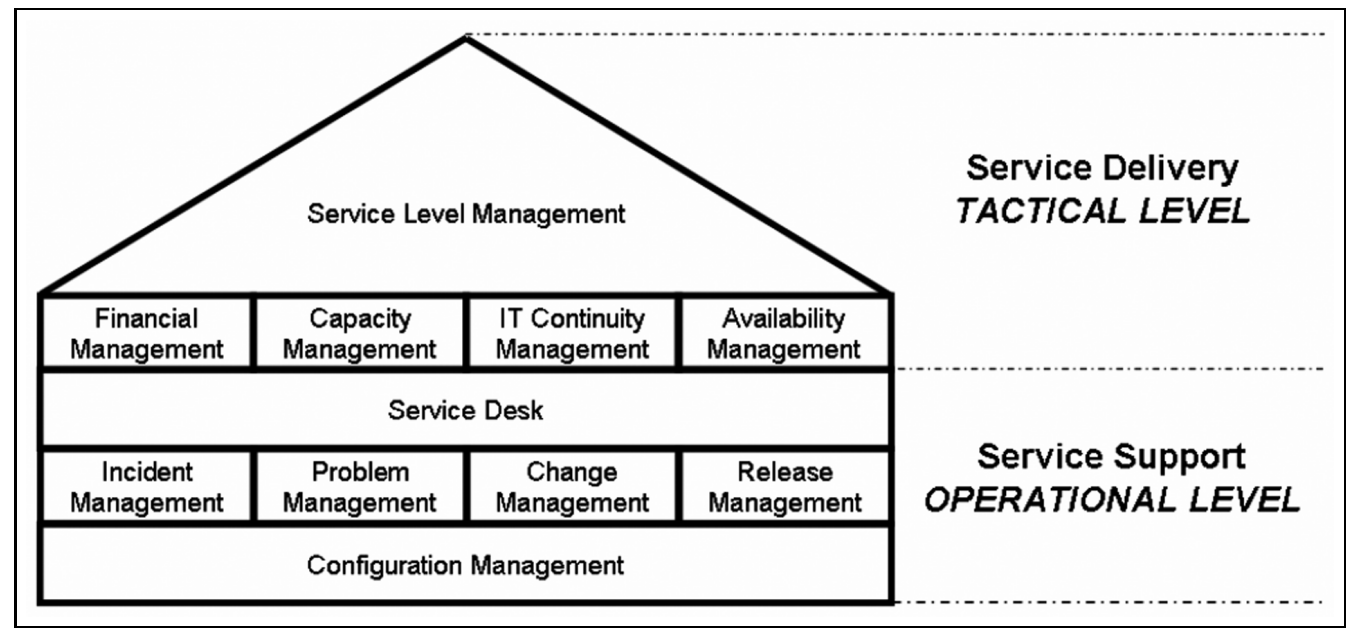

Fig. 2. ITIL core service management functions and processes (source [1]).

and behavioural perspectives and subsequent impact on the environment. This is an excellent representation of the use of ITIL as a continuous process with the aim of maintaining and sustaining best practices.

The ITIL framework for Service Delivery and Support can be accomplished at three levels: (1) The strate- gic level (long term), (2) The tactical (medium term) and (3) The operational level (short term). Figure 2 presents the Key Performance Indicators (KPI) at the tactical and operational levels, which are the main areas, addressed in this research study.

Contemporary research has still focused on exploit- 
ing the ITIL framework for improving IT services. IT Service Support companies focus on ensuring that their customers have appropriate service support for their business functions [11]. This has been demonstrated in [12] where the study presents how the ITIL framework was used for improving the incident management processes in two companies. Just like all other business processes, implementing ITIL framework efficiently depends on building or procuring IT tools that can support them. The basic issue of supporting ITIL with process-oriented tools such as workflow management systems is presented in [7]. Implementing ITIL can be cumbersome and time consuming if one does not follow a roadmap for improvement based on priorities, dependencies, and guidelines [18]. The experience of IT staff and the amount of time devoted for understanding IT needs, and creating an appropriate service management office (SMO) could help improve the success rate of IT services [14]. A case study of managing IT services in finance industry by implementing suggestions that arise from ITIL methodology can also be found in [23].

The following sections report on the research study by first specifying the research method (which was a case study approach) followed by a detailed description of the process analysis, before and after the implementation of the ITILS framework. We then presented the results measuring the overall effectiveness of the ITIL framework implementation. We would like to stress that the ITIL framework is not an evaluation to solve a distinct problem but rather a set of guidelines encouraging a continuous process of IT service support improvements. To that effect, monitoring and controls are required to help in the decision making process leading to this continuously enhanced IT service support. Decision support systems (DSS) are appropriate for this kind of applications and Section 5 elaborates, theoretically, on a recommendation DSS that can be used as an approach to design, implement and integrate into existing IT service support systems. We highlight findings in the conclusion section that follows, including limitations and suggestions for future research.

Therefore, the primary contribution of this study is two folds: practical and theoretical. From a practical perspective, we demonstrate the implementation of ITIL framework and associated guidelines for the reengineering of IT service support processes. We use a case study with empirical data for its measurement and analysis and utilize the results to propose a theoretical decision support system (DSS) for the recommendation of IT service support providing better means of monitoring the need for reengineering

\section{Research method}

\subsection{The case study approach}

A case study methodology is chosen to emphasize and explore factors identified by the ITIL framework [5]. The case study approach will subsequently allow us to identify directions for further investigation. This approach is commonly used as a qualitative method for research in the information systems field [17]. The research in [5] suggested the following three reasons why the case study approach is suitable for information systems: The researcher can study the information system in its natural setting; The researcher can answer "how" and "why" questions; and The case study approach is suitable for studies in which little formal research has been conducted previously.

A case study based research is an exploratory research technique that investigates a contemporary phenomenon within its real-life context [28]. [22] proposed a number of steps that can be used to successfully conduct the case study research. These steps include the definition of the research objective, the selection of the case study, the determination of the data gathering, and the case study analysis techniques. Thereafter, the case study data can be collected and analyzed, and the findings can be summarized in a report. A repository of successful resolutions to the past problems can serve as a tool for preventing or solving the future problems and each resolution can be visualized as a case while accomplishing an intelligent business process reengineering [25]. The business process management systems (BPMS) can actually track an organization's business processes and trigger the need for improvements [10]. The IT tools could provide the means for an enterprise data extraction via process mining; where important events logged can serve as pieces of information that could trigger process improvements [26]. In a nutshell, a business process performs a set of activities and the granularity of improvements at the activity level can accomplish a dynamic management of an enterprise process performance. A service model supports service planning, provisioning, operation and service management at customerprovider-interface [6]. The contemporary business process simulators can be used for decision support systems as well [27]. Likewise, every piece of information is useful for the successful reengineering of business processes.

\subsection{The case}

It is our aim in this study to focus on how to apply 
4 R. Valverde et al. / ITLL-based IT service support process reengineering

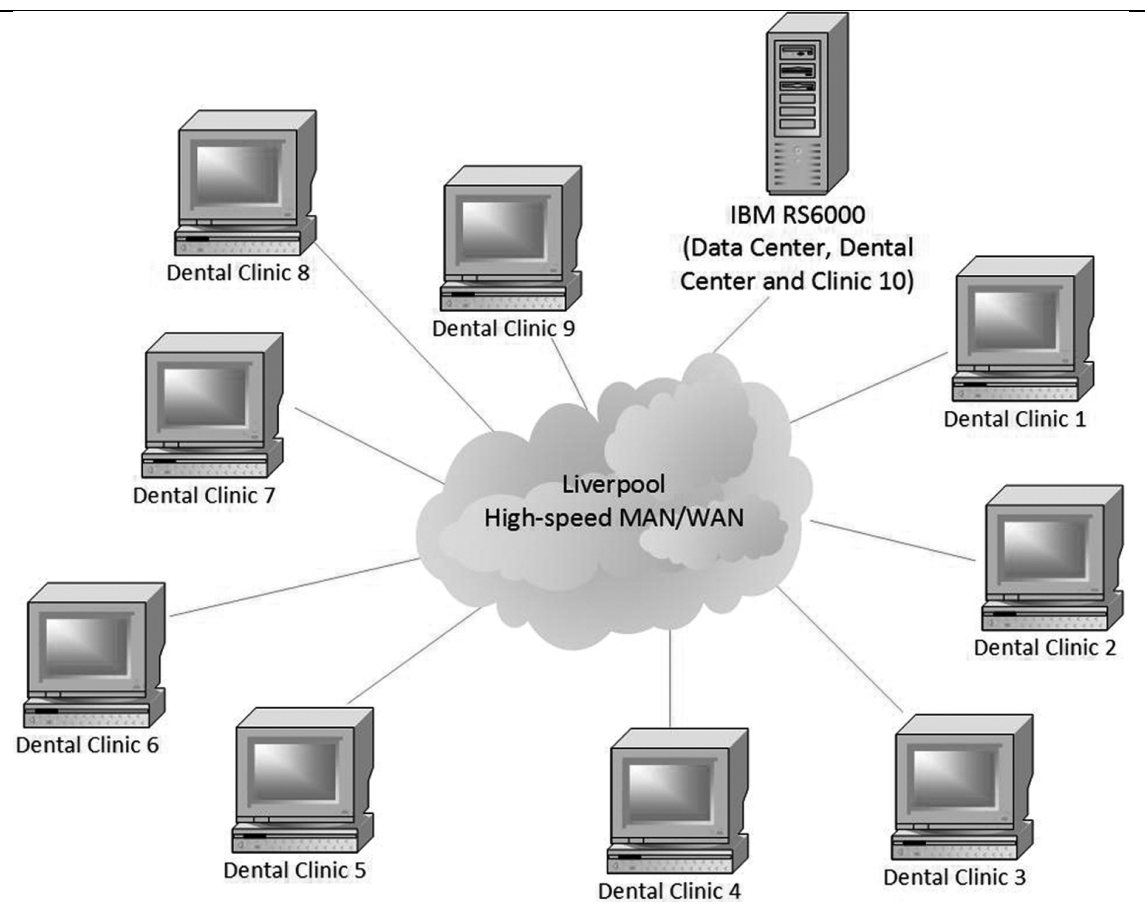

Fig. 3. Dental clinics connected to a central server IBM RS6000. (Colours are visible in the online version of the article; http://dx.doi.org/10. 3233/IDT-130183)

the ITIL framework for the reengineering of IT processes in an organization. The case study selected is that of an IT services company located in Liverpool, UK. The selected company is currently providing several types of support services to many organizations in the UK. For our research, we selected a company that is specializing in dental care. The case entails ten dental clinics in different locations of Liverpool. All these clinics are connected via a high-speed Wide Area Network (WAN). The data is centralized into the IBM RS6000 server located in the main dental center. Workstations are located in the user office and they are connected through the same network as well.

The case will be explained by elaborating on the dental clinic organizational structure, main business services and client base. Since data gathering is an important part in case study research, we utilize the works of [24,28] who identified seven sources of empirical evidence for case studies, as follows:

Documents: Written material sources that include published and unpublished documents, c- ompany reports, memos, letters, agendas, administrative documents, departmental info, reports, email messages, newspaper articles, or any document that presents some evidence of some information,
Archival records: Service records, organizational records, lists of names, survey data, and other such records,

Interviews: An interview can be used for three purposes: as an exploratory device to help identify variables and relations; as the main instrument of the research; and as a supplement to other methods,

Questionnaires: These are structured questions written and supplied to a large number of respondents, commonly spread over a large geographical area for consideration in advance. Respondents fill in the blank spaces and return the questionnaires to the researcher either by post or in person. Sometimes incentives, such as a small gift, are used to encourage recipients to complete the questionnaires,

Direct observation: This occurs when a field visit is conducted during the case study. This technique is useful for providing additional information about a topic being studied. Reliability is enhanced when more than one observer is involved in the task,

Participant-observation: Participant-observation turns the researcher into an active participant in the events being studied, Physical artefacts: Physical artefacts can be too- 


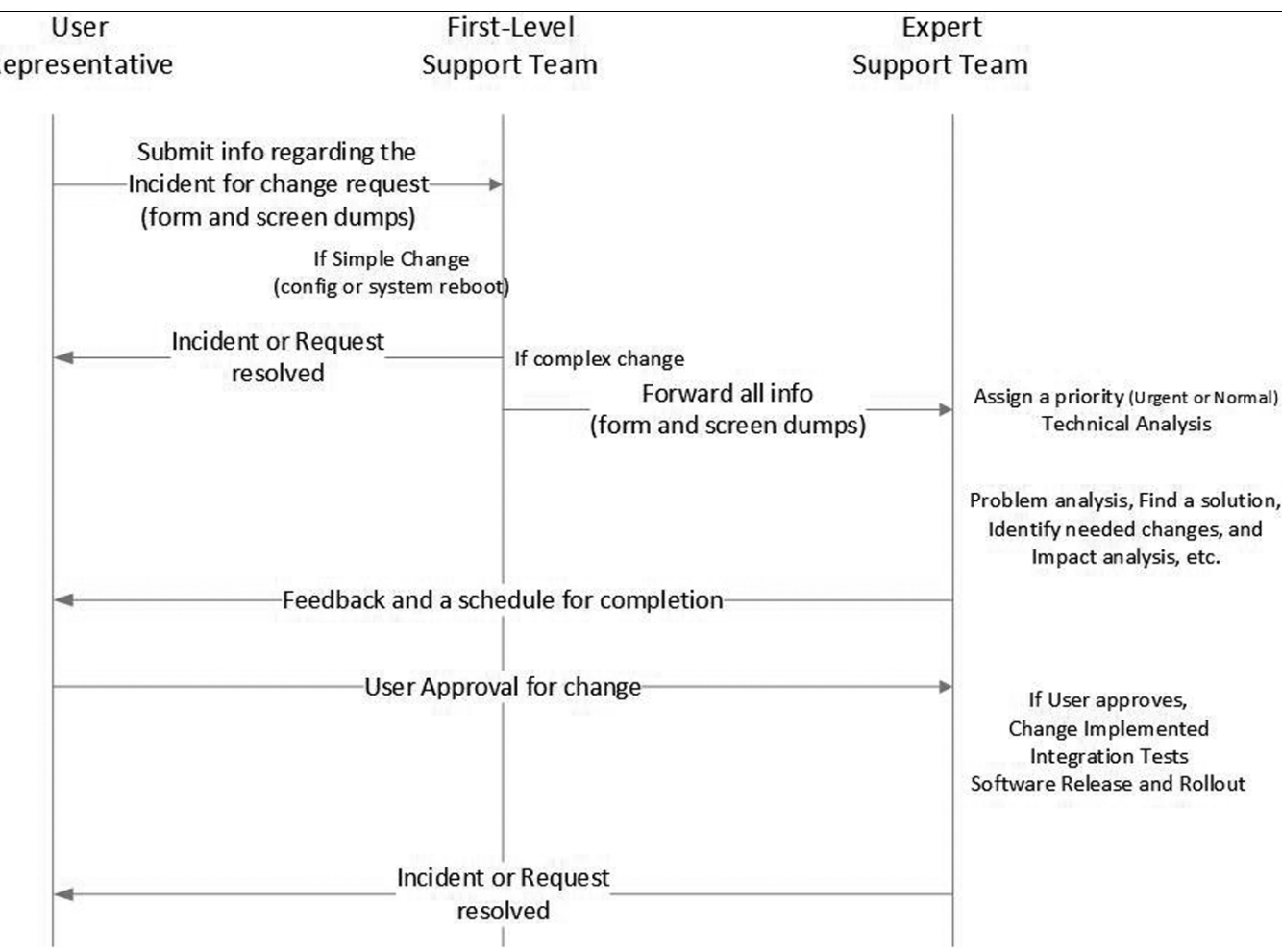

Fig. 4. Workflow process.

1s, instruments, or some other physical evidence that may be collected during the study as part of the field visit. Use of a number of these instruments to obtain data from the same source provides for triangulation as defined in [8].

In our study, we used the questionnaire, review documents, archival records and observations for collecting data. The use of observation as a method of data collection is presented in $[4,5,24]$ where it was shown to work well in case studies research [28].

The service management information support system, SMISS, studied, is a nursing information system developed with the Microsoft Visual Studio development tools. It runs under the Windows operating system; and the workstations are distributed in a local area network. In July 2010, a group of SMISS users and IT representatives were invited to discuss the implementation of ITIL practice as a case study for improving the service. At least one user from each clinic was invited to participate in this discussion.

Microsoft provides package guidance called Microsoft Operations Framework (MOF) that enables organizations to achieve mission-critical system reliability, availability, supportability, and manageability of IT solutions that are built with Microsoft technologies. To achieve operational excellence, Microsoft combines the ITIL best practices in to MOF, and extends MOF to follow the ITIL code of practice $[31,32]$. The MOF provides assessment templates with a set of questions with yes/no answers. Operation guidelines are provided to help users to answer these questions. The questionnaire concerning various performance criteria was prepared using the MOF assessment template. Because the questionnaire has been used before as a successful tool to measure the level of effectiveness of the IT services in an organization according to the MOF guidelines, the answers that were collected from the selected group of users can represent as an important test tool for the system $[31,32]$.

\subsection{Data collection}

The principal author of this article visited the site where the information system was located and utilized to observe its functionality, and how it was used. He collected several documents that identify current business processes and describe their current mode of operational rules. Twenty successful data collection visits were carried out, each lasting an entire day, whereby 

R. Valverde et al. / ITLL-based IT service support process reengineering

meeting all relevant managers and direct contact employees provided the needed subject matter data. Two mangers responsible for operations were also interviewed extensively. In addition, the following main records were collected: SMILE document, MIS procedure document, SLA document and Incident log reports. Subsequently, the researchers performed a full analysis on the data gathered and benchmark the ITIL framework into the IT services operations as it relates to the dental clinic context.

The next step was to study the effectiveness of the ITIL framework to measure the improvements that were achieved on the IT services after the ITIL implementation. To do this, a small portion of the ITIL framework was implemented and one group pretest-postest experiment was conducted as suggested by [30]. The one group pretest-postest experiment is a quasi-experiment in which the subjects in the experimental group were assessed before and after the experiment is administered. The participants of the experiment were selected via convenience sampling in the sense that stakeholders groups were all represented. This sampling technique is guided by obtaining sample units or people who are available for conducting the experimental requirements. This method is justified since the participation in the study was voluntary and it is difficult to anticipate the number of participants in the sample.

A questionnaire was used and administered before and after the implementation of the ITIL framework. The questionnaire, given below, had to be concise and effective in addressing the required data, due to time and monetary constraints. As a result, the questionnaire was defined as "a pre-formulated written set of questions to which respondents record their answers, usually within rather closely defined alternatives" [20]. Participants were assured complete anonymity and the problems of interviewer bias while reducing the respondent's likely reluctance to convey incorrect or controversial information could be mitigated in the analysis [21].

A simple-dichotonomy IT services evaluation questionnaire (shown below) was developed and administered to the participants: the pre-ITIL test (pre-test) and post-ITIL test (post-test). A simple-dichotonomy question requires the respondent to choose two alternatives (Yes and No) [30]. Both tests contained the same questions related to the IT services that were found necessary for evaluation. In order to analyze the data from the questions, and ascertain the general trends, descriptive statistics methods are used. The hypothesis that the
ITIL framework helps to improve IT services is tested 306 by using the t-Test for comparing the mean values of 307 \begin{tabular}{l|l} 
the pre-ITIL and post-ITIL tests [30]. & 308
\end{tabular}

QUESTIONNAIRE - START

\section{Section A: Background information}

1. Name of respondent:

\section{Section B: Satisfaction to the system}

2. Know who should call when there is a computer system problem.

3. Help desk phone number get through easily and support staff pick the phone promptly.

4. Support staff informs you the status of the incident promptly.

5. Support staff fix urgent situation promptly. (e.g. system down)

6. Easy to describe the problem to the support staff.

7. Support staff understands the reporting problem.

8. Incident solved and not occurred again.

9. Help desk able to provide long term solution to solve problem and improve the system

10. Help desk provide different skill expertise to support different type of problems

11. Incident solved and not occurred again.

12. Inventory of the system items including hardware and software are well managed.

13. Change requests impact are analyzed.

14. Changes are tested thoroughly and users are involved in the test.

15. Version of the application system is clearly mentioned and maintained properly.

16. System availability is high.

17. System performance is satisfactory.

18. Enough workstation and printer to use

19. Workstations are free from Virus.

\section{Section C: Clerical officer/dental therapist}

20. Please select the one you will contact when there is a problem.
$\square$ Clinic in charge (senior)
$\square$ Clerical Officer (peer)
$\square$ User Coordination Team
$\square$ Help Desk
$\square$ Other

21. Please select any of the following options which you consider as a problem.
$\square$ Workstation
$\square$ Printer
$\square$ Usage
$\square$ SMILE Application
$\square$ Adhoc query
$\square$ Other

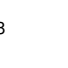

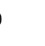

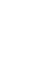

.

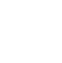

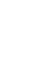

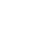

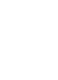

1

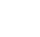

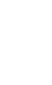

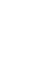


22. Do you ever raise a suggestion or comment to improve the system flow or usage.
$\square$ Yes
$\square$ No

23. Please select the one you will contact if you would like to raise a suggestion or comment.

$\square$ Clinic in charge (senior)

$\square$ Clerical Officer (peer)

$\square$ User Coordination Team

$\square$ Help Desk

$\square$ Other

24. Do you have an identify number for the incident being report?
$\square$ Yes
$\square$ No

25. Do you know the status of the incident being reported?

$$
\square \text { Yes } \square \text { No }
$$

26. Do you aware of the change applied in new release of application system?

$$
\square \text { Yes } \square \text { No }
$$

\section{Section D: Dental office/senior dental therapist

$\square$ Yes $\quad \square$ No $\quad \square$ Not Sure

27. Is there any definition of the responsibility of Help Desk?

28. Is there any fall-back procedure to the change?

29 . Is there a record for all the items in the system?

30 . Is there any disaster recovery procedure in place?

31 . Is there any security procedure to protect the servers and workstations?

32. Is there any security procedure to protect the application data?

33. Does the help desk produce report on the number, type of calls received and processing time of different stages of incidents?

34. Does the help desk produce report on the number of new and completed incidents regularly?

35. Does the help desk produce report on the number of new and completed incidents regularly?

36. Is there any training program provided to the new staff?

37. Is there any refreshment course provided to the staff?

38. Is there any audit performed to check the procedure are followed and the procedure is effective?

39. Is there any key performance indicator to the support service processes?

40. Is there any continuous service improvement plan?

41. Is there tool introduced to improve the support service processes?

\subsection{Workflow}

The process involves a user representative team initiating all requests, a first-level support team for quick fixes, and an expert support team for further analysis and implementations as detailed below.

\subsubsection{Change request form}

- User representative submits the change request form together with all supporting information such as screen dumps or request details etc.

\subsubsection{First-level support team performs preliminary} investigation

- Often, the change request may involve a simple configuration change requiring to enable/disable a feature; in such case, the first-level support team performs the needed change to resolve the issue, reverts back to the user and closes the request.

- If the request is complex, then all information is forwarded to the expert support team.

\subsubsection{Expert support team performs further investigation}

- First, the request is assigned a priority either urgent or normal so that all requests are streamlined based on the urgency.

- Next, all technical impact analysis (TIA) is performed to find out all needed including the impact of change and estimate effort required. The project manager reviews the analysis results especially the effort involved to conduct business impact analysis (BIA) so that the change is negotiated with the user.

- Once the user representative approves and provides a green signal, the project manager gives a green signal to the technical team.

- Technical team implements all software changes involved, conducts sufficient tests including the integration testing involving the user acceptance, and releases the new software which is rolled out where needed.

\section{Process analysis}

Utilizing all the data and information gathered, the scope of all IT services that the company provided to the clinics and used in this case study entailed seven processes that can be identified as follows: 
$\underline{8}$ R. Valverde et al. / ITLL-based IT service support process reengineering

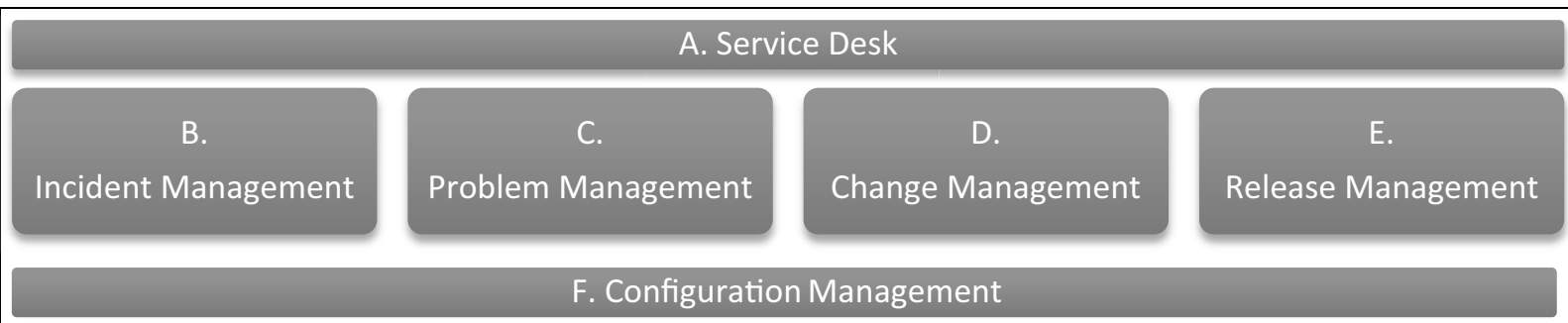

Application Support: e.g. answering phone, fax, email, written request and so on.

System maintenance: Bug fixing, minor system modification and minor data conversion, problem diagnosis, documentation update.

System monitoring and optimization: Periodic system performance monitoring and tuning on the application system.

Production support and Ad-hoc processing requests: Liaise with relevant parties to collect and analyze user requirements, perform data extraction, answer the enquiries on the system data.

Environment and operation support: Perform backup and recovery if needed, assist system software upgrade and patches.

Procurement support: Provide support and advice for capacity planning, on potential technology substitution and cost estimations and on hardware/software installation and relocation.

Planning, drill test and support for disaster recovery and business resumption: Conduct annual disaster recovery and business resumption drill, assist in resumption of business and application in case of disaster.

Project management and reports: Prepare relevant papers and minutes to management for advice, approval and endorsement, prepare periodic progress reports for system performance and achievement, coordinate and attend project related meetings and prepare agenda, minute and other related document.

After analysis of the collected data, processes and problem logs that map the current operations, we developed two models namely one representing the current operational state and after recommendations, a second model representing the new IT services model based on the ITIL guidelines. We present the results of the analysis below as it relates to Fig. 2 above on the ITIL core service management functions and processes. More specifically and as shown below, we present the IT service re-engineering results on: service desk; incident management; problem management; change management; release management; and configuration management

\section{A. Service desk}

A support hotline was established that uses a Single Point of Contact (SPOC) for all incidents.

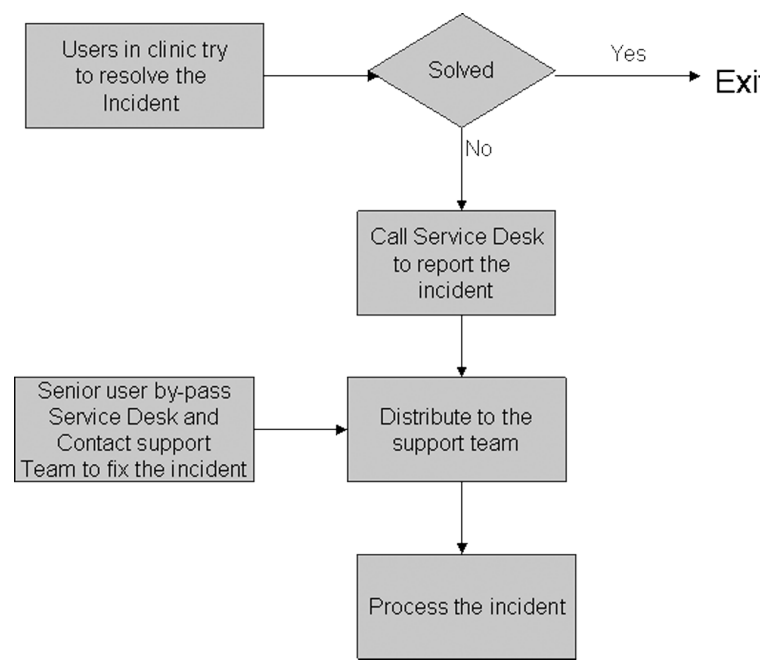

Fig. 5. Current practice of service desk and problems/challenges.

Problems/challenges:

- General users follow the reporting path whereas the senior users by-pass it. The incident will not be logged and the communication among the supporting team members may also break down.

- General users are not well aware of the scope of hotline support. Often, some out-of-scope incidents are not served by the support hotline, and some incidents are not requested that need of customers are not delivered to the support team. IT infrastructure and scope of services should enable its users to customize their expectations. Any suggestions for enhancement should be encouraged for improving and maintaining a right balance among people, processes and technology.

Schema for benchmarking with ITIL. Guidelines (GL) of ITIL framework for service desk are provided in Fig. 6. 


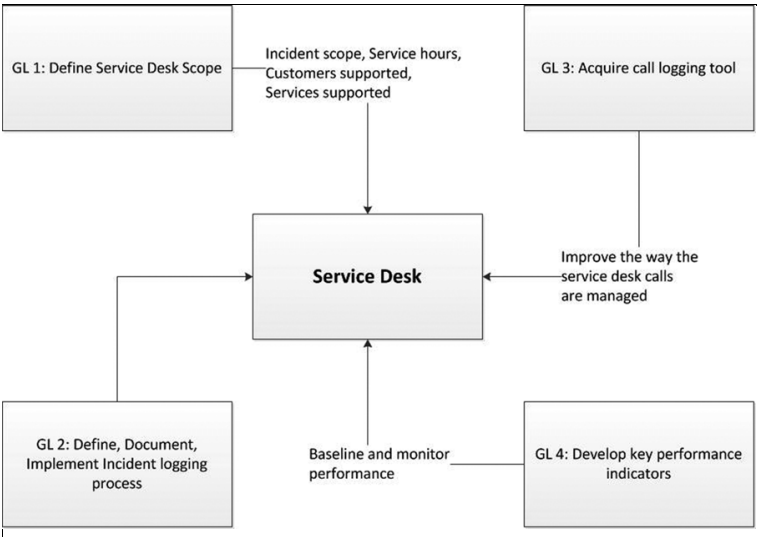

Fig. 6. Service desk guidelines.

Recommendations:

According to $G L 1$, the system should define: Service hours; Contact point after service hours including mobile phone, email and paper; Problem incidents including hardware; software; application and office automation; Change request; Ad-hoc query; Coordinate with the supplier (of $\mathrm{h} / \mathrm{w}$ and $\mathrm{s} / \mathrm{w}$ ) for procurement and maintenance issues; Nature of incidents (Application Help Desk; "Fire" Fighting; Problem management; System Administration; Ad-hoc processing request; Minor enhancement; Management Activities).

According to GL 2, Contact points of business user, IT representative, clinic contact, hardware and software supplier and network provider are maintained in the list of contacts for Service Desk. There is a need to improve the message system in the application for broadcasting and point-to-point communication. Incidents reported through any channel should be logged by the service desk in order to enforce the "single point of contact". The dissemination of an incident should be performed by the service desk accordingly. For incidents classified as medium and severe, the service desk supervisor should call the users to ensure satisfaction of the solution provided.

According to GL 3, Microsoft Excel is used to keep the call logs. Excel macro can be used to facilitate the $\log$ entry and to generate statistics.

According to GL 4, the key performance indicators (KPI) to measure Service Desk performance are:

- Time to log incident to the database for calls via email, phone, or voice mail,

- Time to acknowledge the user,

- Time to categorize and prioritize the incident,

- Time to start the resolving action,

- Time to complete the action, and

- Percentage of number of satisfaction over the number of medium and high priority incidents.

\section{B. Incident management}

Incident handling procedures was established as shown in Fig. 7.

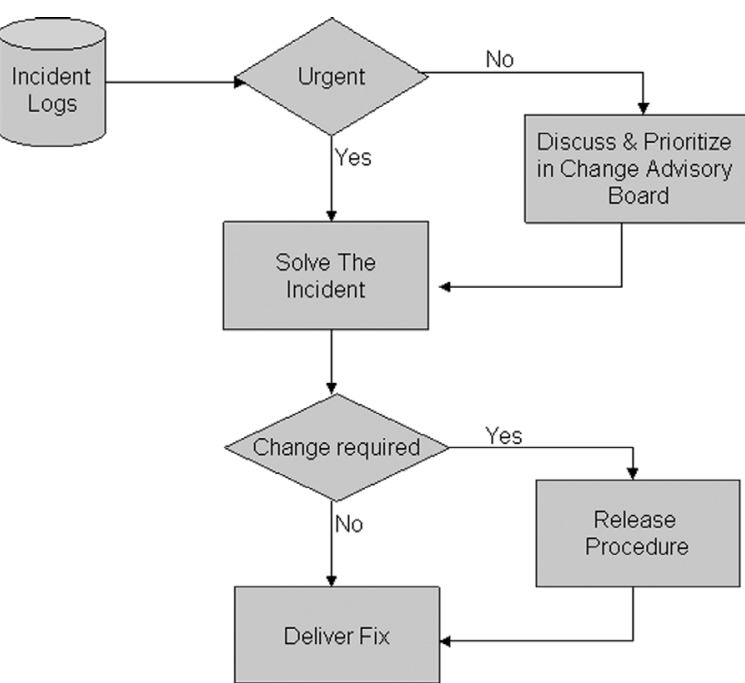

Fig. 7. Current practice of incident management.

Problems/challenges:

- The logging information was not enough to measure the performance against the server level requirement. There was no escalation procedure defined and support team performance was not measured by any key performance indicator.

- Each service desk staff actually maintained a separate log. The incidents were discussed and prioritized by the Change Advisory Board, but other users were not able to learn the status of the incident being reported.

Schema for benchmarking with ITIL. Guidelines (GL) of ITIL framework for incident management are provided in Fig. 8.

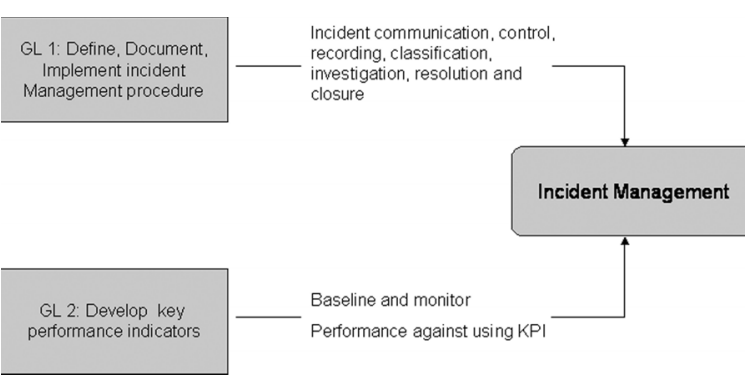

Fig. 8. Incident management guidelines. 
10 R. Valverde et al. / ITLL-based IT service support process reengineering

Recommendations:

According to GL 1, the system should:

- Maintain centralized database for incident log;

- Content of the incident log should include; Unique identity number; Report date and time; Log date and time; Type of call (written, phone, voice message or verbal); Nature of incident (enhancement, ad-hoc request, hardware, software, network, application); Acknowledgement date and time; Priority; Time to return to office in case of non office hour; Date and time to determine priority of the incident; Date and time of written reply; Date and time of analysis result completed; Date and time of resolution; Resolution; Date and time of third party complete the case (resolution is calling the third party); Down time and number of workstations affected; Staff codes perform the receiving, logging, acknowledgement and resolving the incident; Unique identity number of the configuration item; Effort estimation; Effort spent

- Type of the incident: Application (custom developed programs); Hardware; Software (for example, operating system or system software); Network; Ad-hoc query; Enhancement; Query about office automation tool; Query about application usage; Other

- Priority of the incident: Urgent (complete as soon as possible); High (complete in three days); Medium (complete in two weeks); Low (complete in two months)

- Escalation procedure by reporting to support team manager if the incident cannot be solved within the period defined.

- Incidents log is posted to the Intranet site so that users are able to inquire the status of the incident in the $\log$.

According to GL 2, the followings are the KPIs for Incident Management:

- Number of incidents in open state,

- Number of incidents reported within the month,

- Number of incidents solved within the month, and

- Number of incidents in closing state.

\section{Problem management}

The current practice of Service Management Information Support System (SMISS) was mainly reactive, i.e. the support team solved the reported incidents. There was no procedure defined for proactive problem management (PM).

Problems/challenges:
- The number of incidents was not reduced and the system could not be stabilized.

- Users stopped reporting the repeated incidents and restarted the system to solve the incidents. User satisfaction dropped and blamed the system informally.

- Support team prepared the data extraction manually for each clinic and repeated periodically. User data services effort was not reduced.

Schema for benchmarking with ITIL. Guidelines (GL) of ITIL framework for problem management are provided in Fig. 9.

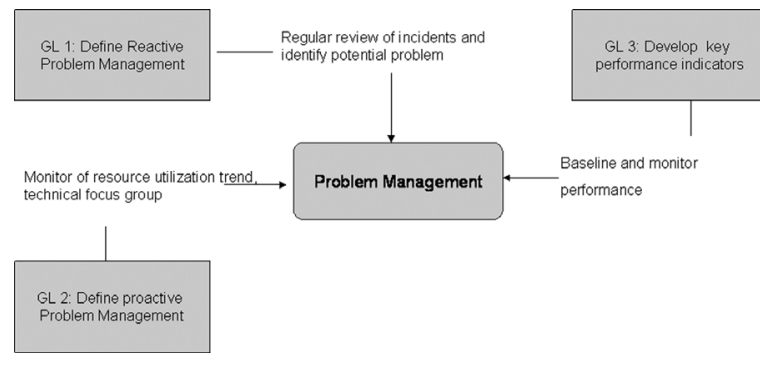

Fig. 9. Problem management guidelines.

Recommendations:

According to GL 1, the system should define a reactive problem management, as follows:

- Conduct monthly review incidents should identify chronic problems by verifying the number of occurrences of the same or similar incidents.

- Build a problem log database using a unique reference number for each problem. This number is updated to the incidents $\log$ and incident number should be updated to the problem log for cross reference. It is possible to have multiple incidents pointing to the same problem.

The problem log should have the following attributes: Problem reference number; Date and time of creation; Date and time of solution; Created by; Solved by; Major type (hardware, software or network); Minor type (for example servers, workstation, MS word or router); Supplier (for example, Microsoft or CISCO); Description of problem; Incident numbers.

According to GL 2, the system should define a proactive problem management. In general, the problems that are related to the network and CPU, could gradually downgrade the system performance. Users report incidents related to system performance when it becomes unacceptable. The resource utilization trend should be monitored to determine if the system (network or CPU) performance has fallen below an acceptable threshold. 
- Build in-house technical focus groups. A focus group for SMISS could monitor: Windows, Unix, Web, Development tool, or a Database.

- A focus group will be able to solve any technical incidents more efficiently in a proactive manner. The focus group should keep the support team informed of any possible problems that could occur in a timely manner.

According to GL 3, the KPIs are:

- Number of incidents,

- Average number of incidents related to a problem, and

- Number of problems.

\section{Change management}

Change management procedure was established to address change requests, as shown in Fig. 10.

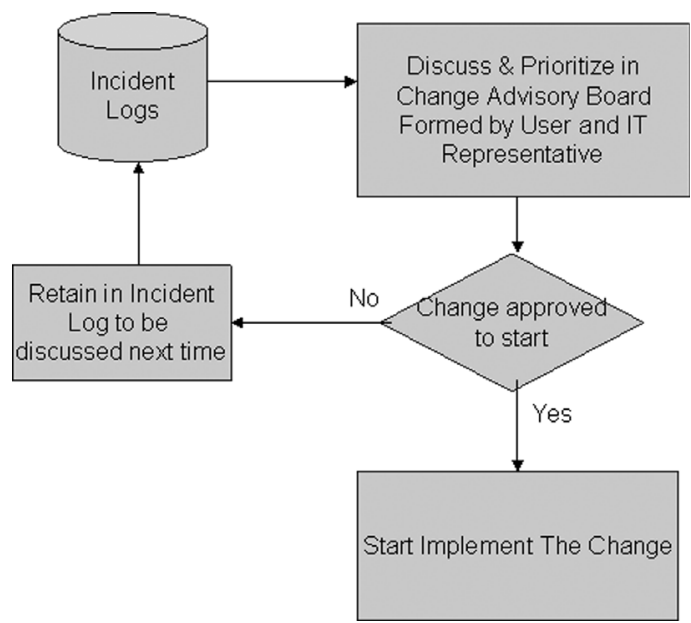

Fig. 10. Current practice of change management and problems/challenges.

\section{Problems/challenges:}

- The maintenance board does not include all stakeholders (representatives from all functional groups). This reduces the quality of decision making which would not be effective and efficient.

- The procedure for issuing Request For Change (RFC) is specified; however the duplicated and unpractical requests were not filtered before passing to the Change Advisory Board (CAB). The impact analysis could estimate the effort and the scheduled delay for implementation; however such impact analysis was not conducted.

- There were no key performance indicators for measuring the changes in the system performance.
Schema for benchmarking with ITIL. Guidelines (GL) of ITIL framework for change management are provided in Fig. 11.

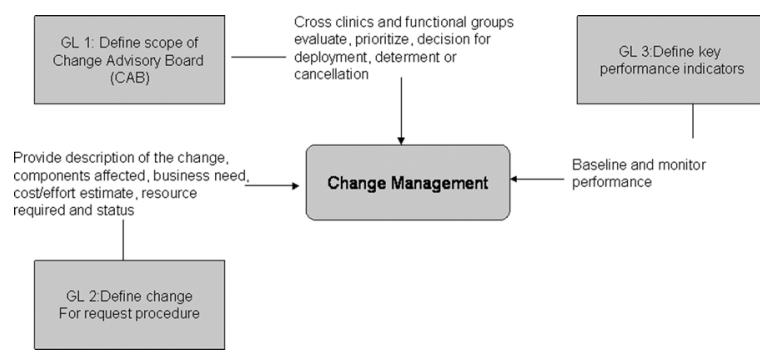

Fig. 11. Change management guidelines.

\section{Recommendations:}

According to GL1, the system should define the scope of the $\mathrm{CAB}$ where it should be composed of representatives from both IT department and clinic staff. The agenda and incidents to be discussed should be distributed before the $\mathrm{CAB}$ meeting and each functional group should arrange a representative to attend the meeting. The $\mathrm{CAB}$ would make decisions for deployment, further analysis, approval or cancellation of changes.

According to GL2, the procedure of Request for Change (RFC) should be:

- Incidents that need change should be reviewed before the $\mathrm{CAB}$ meeting. Any duplication and unnecessary incidents should be filtered. The status of the filtered incidents will be distributed to the $\mathrm{CAB}$ members and the requestor.

- The board should analyze the technical and business impact of the request. The analysis result should be assessed by the CAB.

- If the man-days required exceed the scheduled limit (5 man-days) for the service that will affect the normal support service, then the CAB should determine whether to acquire extra budget for the request or to do it with support team resource but it has lower priority than the service request.

- Change for request should be issued after CAB approves the request. The priority of change request should be high, medium or low. The rollout schedule should also be determined by the CAB. The rollout schedule should be documented and distributed.

According to GL3, the following is a list of the KPIs for Change Management:

- Number of failed changes implemented, 
12 R. Valverde et al. / ITLL-based IT service support process reengineering

- Number of emergency changes implemented,

- Number of occurrences of the process being circumvented,

- Percentages of these numbers, and

- Critical level of percentage to be defined and it should be escalated once the level is reached

\section{E. Release management}

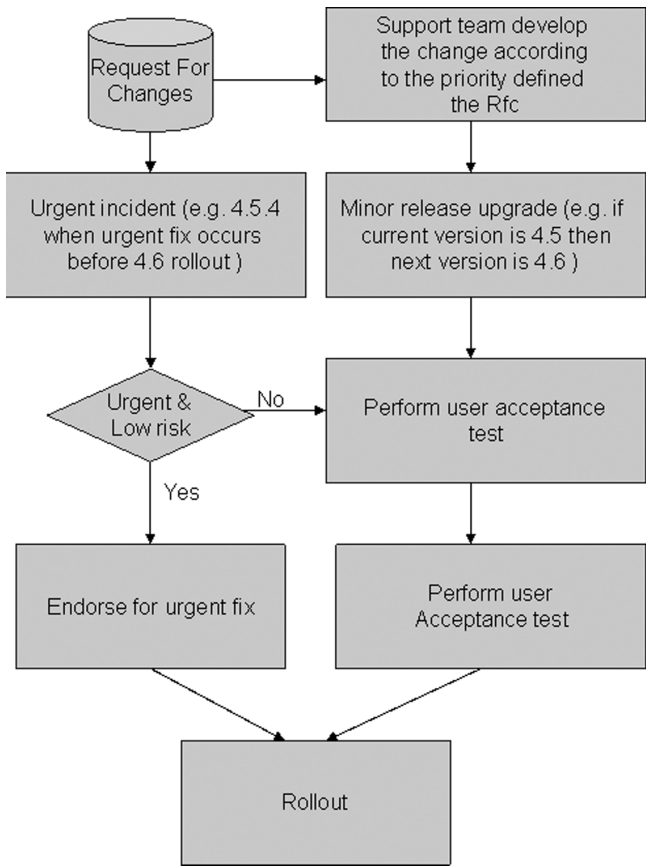

Fig. 12. Current practice of release management and problems/challenges.

Problems/challenges:

- There was no release policy; and the support team performed as many changes as possible for each release. Usually the low priority RFCs were left outstanding.

- There was no policy for Hardware and System software upgrades.

- There was no communication to the users about the changes in each release.

- There was no fallback plan in case of unsuccessful releases. There was no plan to merge the emergency fixes and into normal releases.

- Distribution and installation of new releases were error prone since every workstation has to be installed separately.

Schema for benchmarking with ITIL. Guidelines (GL) of ITIL framework for release management are provided in Fig. 13.

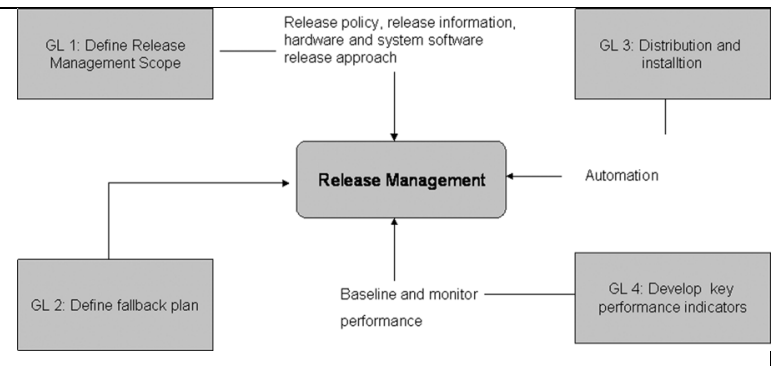

Fig. 13. Release management guidelines.

Recommendations:

According to GL 1, the system should have the following release policy:

- Adopt Package Releases, each consisting a series of changes of high and low priority requests. The high priority requests should be completed before any of low priority requests.

- Prepare rollout schedule and put it in the Intranet and make available to all users.

- Hardware and system software upgrades (e.g. a Windows patch) must be tested on pilot workstation before a full rollout. The pilot test should be conducted on a frequently used workstation for a period of at least two weeks to prove that the upgrade is working and stable.

According to GL 2, a fallback plan should be established:

- Use version control tool to keep the previous release for fallback use.

- Compare the urgent fix version with the next release; apply the delta to the next release.

- Retrieve correct previous release in case of fallback.

According to GL 3, distribution and installation should be enhanced:

- Inform user of the release and the content in two days in advance.

- Automate the distribution and installation by developing an auto-installation module to the system. The module upgrades the workstation module once a new version is found.

According to $G L 4$, the followings are the KPIs for Incident Management:

- Number of problem incidents caused, and

- Number of occurrences of the process being circumvented.

\section{F. Configuration management}

Configuration management, as shown in Fig. 14. 


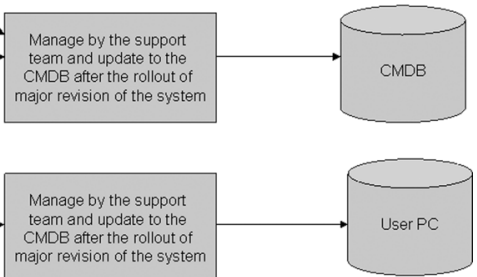

Fig. 14. Current practice of configuration management and problems/challenges.

\section{Problems/challenges}

- Hardware item was not included in the database since the configuration information of hardware was not available.

- Change Management Database (CMDB) and user prepared materials were not stored centrally and not shared by related parties, and the materials prepared between the parties were not related.

- There were no change records to the configuration items (CIs). The accuracy of the CMDB was not ensured.

Schema for benchmarking with ITIL. Guidelines (GL) of ITIL framework for configuration management are provided in Fig. 15.

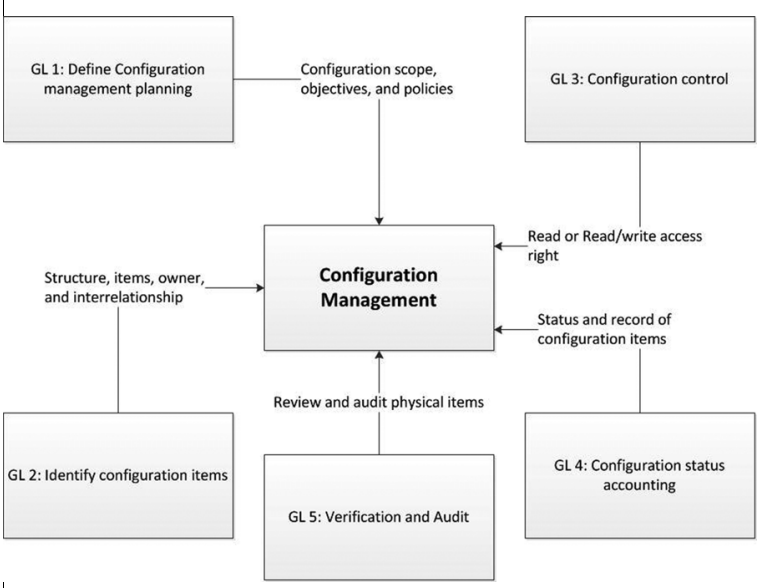

Fig. 15. Configuration management guidelines.

\section{Recommendations:}

According to GL 1, the system should prepare a configuration management plan:

- Identify the configuration items
* Hardware - workstation, monitor, printers, external disk, tape, uninterrupted power supply, server, printer, bar code scanner, Chinese input device and rack.

* Software - operating system, database server, development tool, version control software. These are the software developed by other vendors for general use.

* Program source - all UNIX and Windows programs custom developed for the customer that the support service is being provided.

* Job script - job scripts to apply change to the production environment.

* System documentation - meeting minute and agenda, incident $\log$, feasibility study, proposal, project plan, analysis \& design, system specification, program specification, operation manual, test plan and result, acceptance, approval forms of change implementation, and impact analysis.

- Deployment of version control tool to manage the softcopy configuration items. The Software, Program Source, Job Script and System Documentations are stored and protected in a Definitive Software Library (DSL). Standardized configurations of Hardware are stored in the Definitive Hardware Store (DHS).

- CMDB ready in the Intranet site to enable user inquiry.

According to GL 2, the system should establish the followings configuration structure:

- Identity the owner of the CIs.

- Grant different access right to Read or Read/Write of the CIs.

- Group the materials according to the item types defined; they are Hardware, Software, Program Source, Job Script and System Documentation. For example, the user guide and business logic description prepared by user should be grouped under system documentation.

According to GL 3, the following controls should be applied:

- A unique identity code is assigned to each CI.

- The identity code is kept in the incident, problem logs and release document as records to the change of the CIs

According to GL 4, status accounting should be performed. 


\section{ITIL framework implementation, testing and results}

The questionnaire assessment templates provided by the MOF, including KPI-related questions, was administered [31]. Because the questionnaire has been used before as a successful tool to measure the level of effectiveness of the IT services in an organization, the answers that were collected can represent an important test tool for the recommended system.

All ITIL functions and processes are tested with the exception of "Financial Management" because the "Simplified Data Communication and Sharing" government best practices (SDCS) were adopted for the financial processes. While we were conducting this research, there was a security audit process-taking place by a third party vendor, as well. This was an opportune timing since most of the users in the test group were also participating in the security audit process to measure the level of effectiveness of Security Management, and access to the users was facilitated.

In November 2010, the same group of SMISS users and IT representatives were invited to participate in the post-test. The answers to the pre-test and post-test data using the same questionnaire are presented in Tables 1 to 12 . The count of positive feedback is presented in the frequency distribution table, with associated means and variances. In all tables and figures below:

$$
\begin{aligned}
& \text { - Sample size: } 20 \\
& \text { _ } \rightarrow \text { Pretest }
\end{aligned}
$$

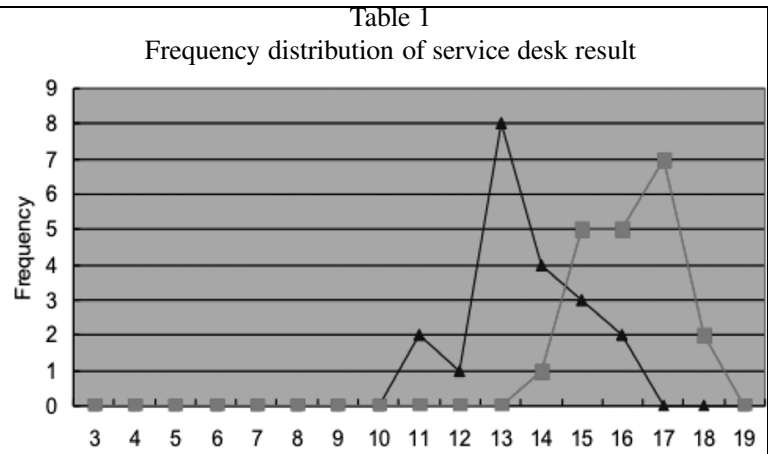

Pretest: $M=13.6 ; V=1.9$; posttest: $M=16.2 ; V=1.2$.

Table 2

Frequency distribution of incident management

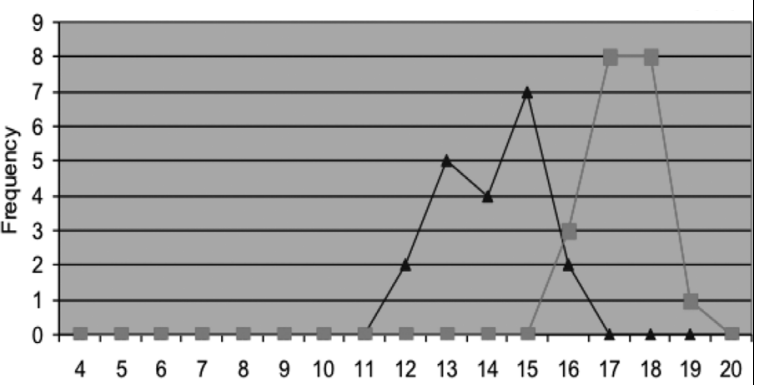

Pretest: $M=14.1 ; V=1.4$; posttest: $M=17.3 ; V=0.7$.

Table 3

Frequency distribution of problem management

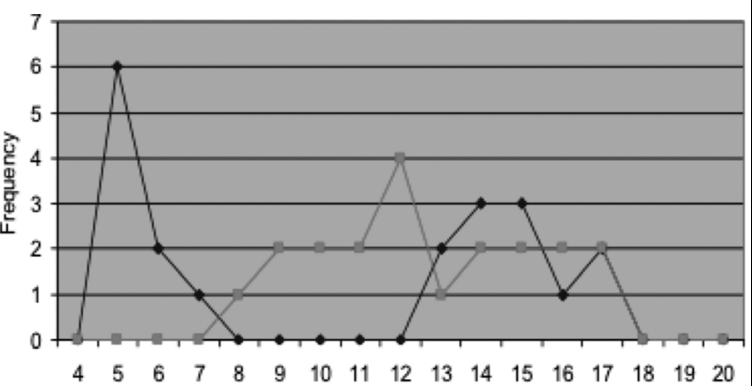

Pretest: $M=10.6 ; V=24.2$; posttest: $M=12.7 ; V=7.6$.

Table 4

Frequency distribution of configuration management

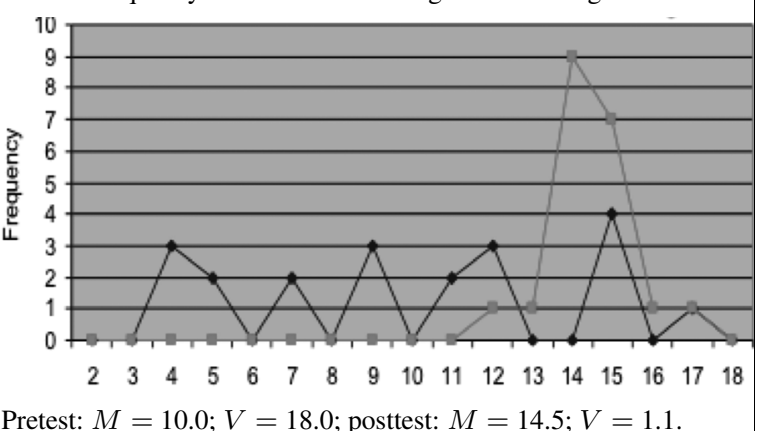




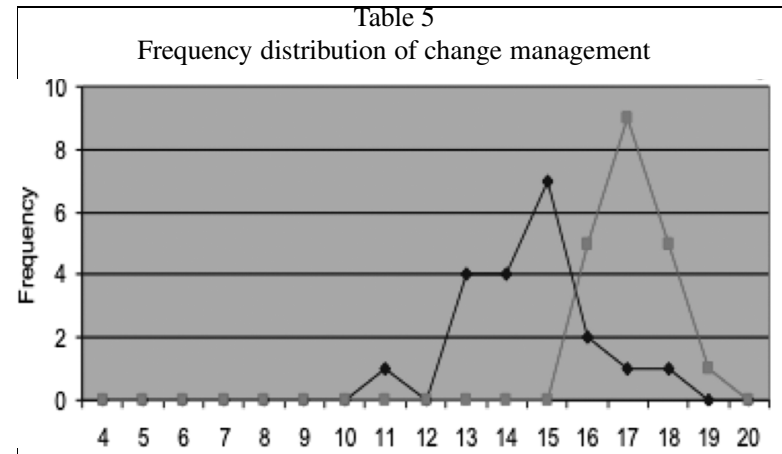

Pretest: $M=14.6 ; V=2.5$; posttest: $M=17.1 ; V=0.7$.

Table 6

Frequency distribution of release management

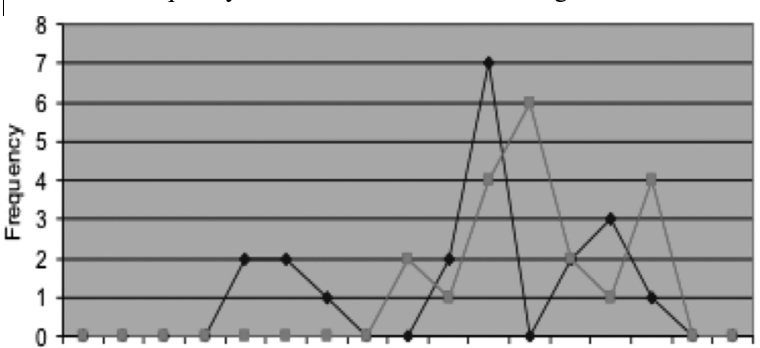

$\begin{array}{llllllllllllllll}6 & 7 & 8 & 9 & 10 & 11 & 12 & 13 & 14 & 15 & 16 & 17 & 18 & 19 & 20 & 21\end{array}$

Pretest: $M=15.4 ; V=9.7$; posttest: $M=17.2 ; V=3.5$.

Table 7

Frequency distribution of service level management

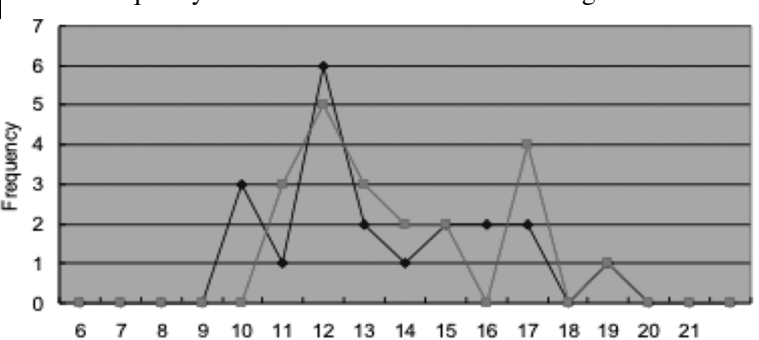

Pretest: $M=13.4 ; V=6.8$; posttest: $M=13.8 ; V=5.9$.

Table 8

Frequency distribution of capacity management

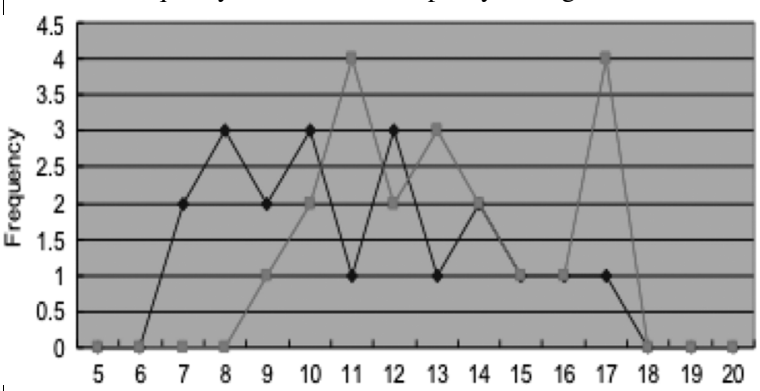

Pretest: $M=11.1 ; V=9.0$; posttest: $M=13.1 ; V=6.9$.
Frequency distribution of IT service continuity management

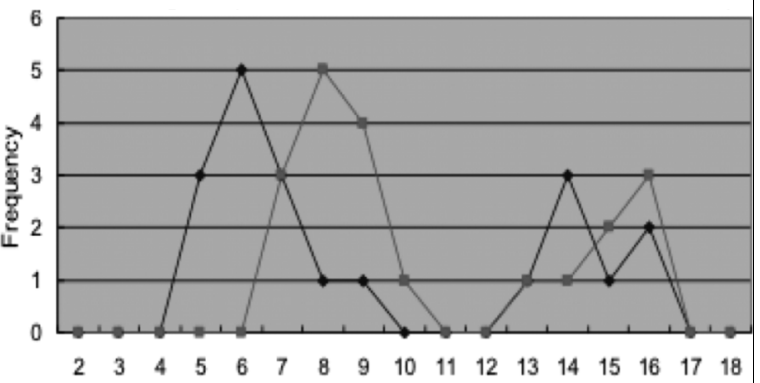

Pretest: $M=9.2 ; V=17.4$; posttest: $M=10.6 ; V=11.9$.

Table 10

Frequency distribution of availability management

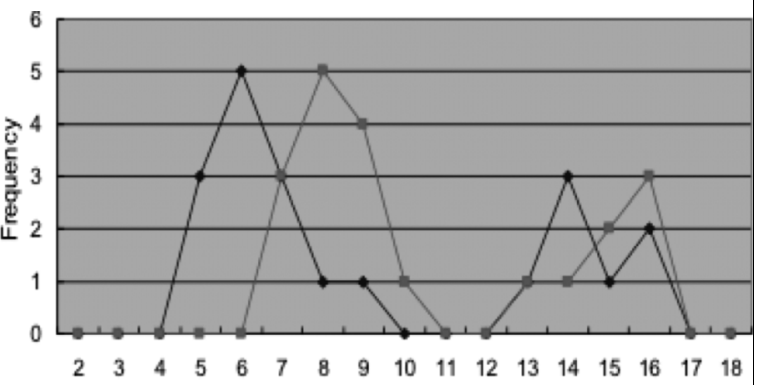

Pretest: $M=9.8 ; V=14.0$; posttest: $M=13.1 ; V=5.4$.

Table 11

Frequency distribution of security management

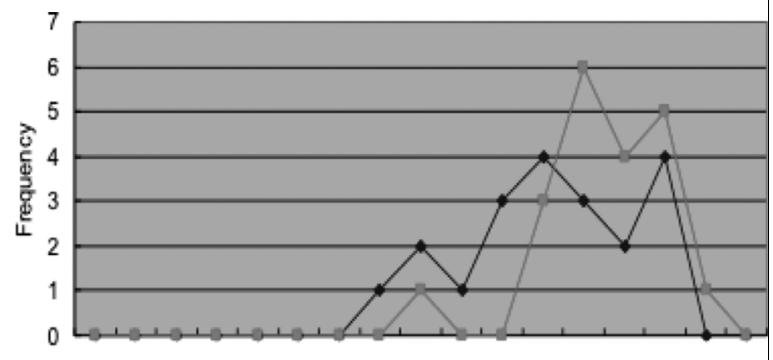

$\begin{array}{lllllllllllllllll}5 & 6 & 7 & 8 & 9 & 10 & 11 & 12 & 13 & 14 & 15 & 16 & 17 & 18 & 19 & 20 & 21\end{array}$ Pretest: $M=16.2 ; V=4.6$; posttest: $M=17.5 ; V=2.5$.

The mean values of pre-test and post-test results are compared to check if there is an improvement in the positive feedback to the concerned support service. The mean values were tested using the t-Student test, and the t-values were calculated by using the following formula [30]:

t-value $=($ Mean of post-test - Mean of pre-test $) /$ square root (Variance of post-test/ Sample size of post-test + Variance of pre-test/Sample size of pre-test)

Note: Alpha level $=0.05$ of one tail test; Degree 
16 R. Valverde et al. / ITLL-based IT service support process reengineering

\begin{tabular}{|c|c|c|c|c|c|c|c|c|}
\hline \multicolumn{9}{|c|}{$\begin{array}{l}\text { Table } 12 \\
\text { Null Hypothesis of the services }\end{array}$} \\
\hline & \multicolumn{3}{|c|}{ Pre-test } & \multicolumn{3}{|c|}{ Post-test } & \multirow[b]{2}{*}{ t-value } & \multirow[b]{2}{*}{ Null hypothesis } \\
\hline & $\%$ Yes & Mean & Variance & $\%$ Yes & Mean & Variance & & \\
\hline Service desk & 75 & 13.6 & 1.9 & 90 & 16.2 & 1.2 & 6.66 & Reject \\
\hline Incidence management & 74 & 14.1 & 1.5 & 91 & 17.3 & 0.7 & 9.97 & Reject \\
\hline Problem management (PM) & 56 & 10.6 & 24.1 & 67 & 12.7 & 7.6 & 1.63 & Accept \\
\hline Configuration management & 58 & 9.9 & 18.0 & 85 & 14.5 & 1.1 & 4.66 & Reject \\
\hline Change management & 77 & 14.6 & 2.5 & 90 & 17.1 & 0.7 & 6.38 & Reject \\
\hline Release management & 74 & 15.4 & 9.7 & 82 & 17.2 & 3.5 & 2.15 & Reject \\
\hline Service level management (SLM) & 64 & 13.4 & 6.8 & 66 & 13.9 & 5.9 & 0.57 & Accept \\
\hline Capacity management & 58 & 11.1 & 9.0 & 69 & 13.1 & 6.9 & 2.30 & Reject \\
\hline IT service continuity management (SM) & 54 & 9.3 & 17.4 & 62 & 10.6 & 11.9 & 1.12 & Accept \\
\hline Availability management & 58 & 9.8 & 14.0 & 77 & 13.1 & 5.4 & 3.30 & Reject \\
\hline Security management & 81 & 16.2 & 4.6 & 88 & 17.5 & 2.5 & 2.19 & Reject \\
\hline
\end{tabular}

Note: $\%$ of Yes - percentage of positive answer for the group.

of freedo $m=$ sample size of pretest + sample size of posttest $-2=38$. According t-distribution significance table, the critical value is 1.684 for one tail test. As shown in Table 12, as far a the Null Hypothesis is concerned - there is no difference between the pretest and posttest sample means for each of ITIL function and processes.

Table 12 presents the percentage of participants answering "Yes", before and after implementing ITIL framework which indicates the effect of ITIL and the improvement achieved. From that table, the null hypothesis of no difference between pretest and posttest mean values for problem management, service level management and IT service continuity management are accepted, which implies that there is no change in the positive feedback from the test group after the ITIL practices have been implemented. The null hypothesis of the other ITIL processes is rejected since the mean values of posttest are larger than the mean values of pretest indicating that improvement due to ITIL practices implementation has been achieved. T-value analysis further supports the conclusions in Table 12.

The t-test demonstrates whether the effect of the implementation of the ITIL practice guidelines into the service process improved satisfaction. To determine which process has to be further improved, the percentage of positive feedback is used. By setting targets of $80 \%$, PM, SLM and SM would have to be further improved. The SM is the only process that has a pretest percentage over $80 \%$; the third party security audit could be the reason for the scenario and the test of SM then cannot be concluded.

\section{DSS interface to IT service support}

When considering the IT service support as an information systems that manages associated operations, the ITIL and CMMI (capability maturity model integration) can be used as part of the design and implementation of the DSS. The ITIL provides a framework for operations and infrastructure while the CMMI provides a set of improvement goals and a point of reference for appraising current processes. Both CMMI and ITIL improve the IT service support process as they allow for the improvement of software quality and decreasing the cost of quality software systems. Within that same domain, the decision making process which utilizes both knowledge and information has the potential to achieve the desired outcomes (mainly, monitoring, control, improved system quality, enhanced IT service support, and cost reductions). The knowledge management process involves gathering, analyzing, storing, and sharing knowledge and information within the organization [19]. Information provides clues to resolve an uncertainty and complexity of an issue, while the knowledge helps in understanding the ambiguity around the issues. A decision support system aids in decision making under the conditions of uncertainty and complexity [29].

The IT support process reengineering is an ongoing process, which requires a continuous monitoring of the KPIs at an operational level and tactical level. The various targets such as green light, yellow light, and red light signals can be established for each KPI. Recent advancements in the telecommunications and computer networking technologies are able to connect any distant and disparate systems together, making it possible to control a remote system from anywhere, based on decisions made in effective management of IT service support process. A decision support system continuously monitors the KPIs and signals appropriate actions that can be performed on any remote system as depicted in Fig. 16. To the best knowledge of the authors, decision support systems for IT service support 


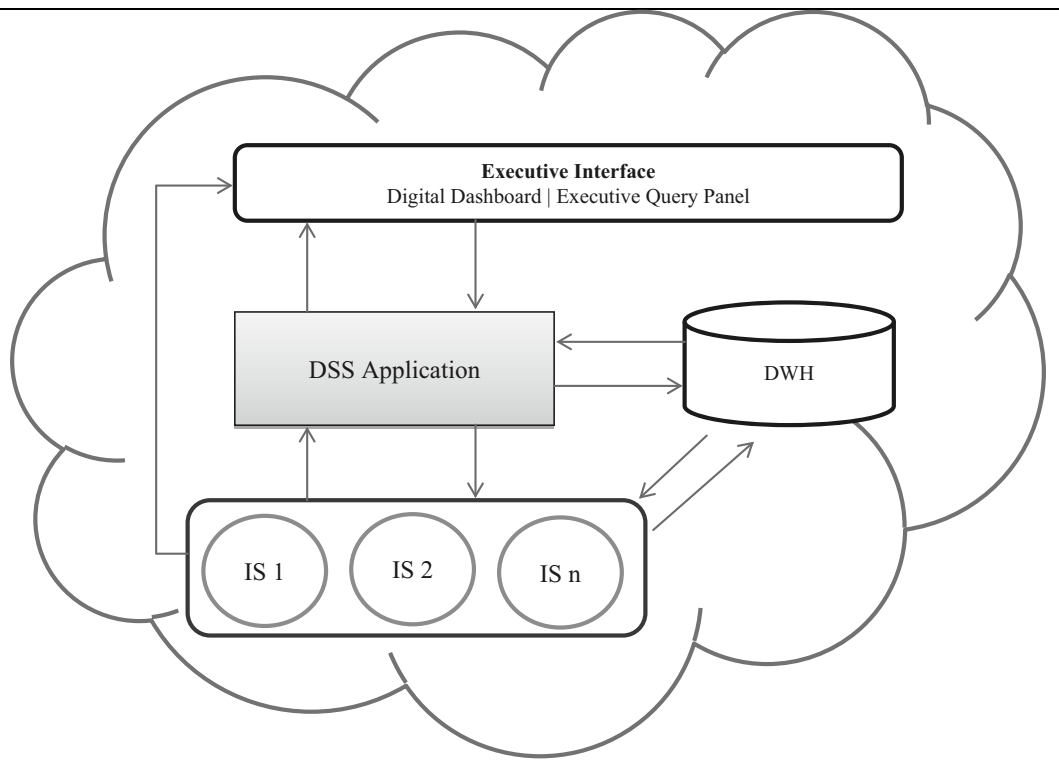

Fig. 16. A typical decision support system. (Colours are visible in the online version of the article; http://dx.doi.org/10.3233/IDT-130182)

with embedded ITIL guidelines have not been implemented yet. Figure 16 therefore, adapted from Vahidov et al. 2012, proposes such a DSS architecture that can be implemented. Other similar DSSs have been implemented but not including ITIL and CMMI.

The software components of Intranet and the information systems (IS) connected to it, are managed by the network performance management system (NPMS). A data warehouse (DWH) system is also connected to the network that extracts, transforms and loads (ETL) all needed data related to the KPIs of IT service support process. The Decision Support Server (DSS) again interfaces with the DWH builds the KPIs of IT service support process and displays them on a digital dashboard of an IT executive responsible for supporting all IT services. Both DWH and DSS server can be housed on the same hardware platform for simplicity or on different systems that are connected together. An IT executive who manages IT service support process runs a DSS client that provides a realtime digital dashboard with all KPIs and alarms suggesting IT service actions. Furthermore, the executive can also perform queries for addional information if needed. The proposed DSS application futher improves the IT service support process and serves as tool for an effective on-going reengineering of IT service support process.

\subsection{Knowledge management}

Knowledge is power and the meaning of the word has been discussed for thousands of years. Today, knowledge has become the key economic resource. ${ }_{1003}$ To that effect, interest in, and attention to, knowledge 1004 management systems has significantly increased in 1005 academic institutions, organizations, NGOs and governments alike. Managing knowledge though is challenging and continues to be so to this day. For one thing, the management of knowledge is heavily information technology (IT) dependent, and the creation and utilization of knowledge is dependent on the individuals' expertise, which is tacit, and may be unstructured, and external.

Today, computers are used to process knowledge for decision support (storing, and transferring). This expertise and experience processing of managing knowledge is presented to individuals for interpretation. With interpretation, individuals can further learn and gain knowledge, hence extend and expand the existing knowledge. Therefore, the knowledge management where individuals interact with computers to learn and gain knowledge can be viewed as an active process of learning. Knowledge management therefore, can be viewed as getting the right information to the right people at the right time, where an individuals' intelligence entails mainly products, operations, and content.

\subsection{Decision support recommendation system}

A decision support system can be focused on pro- ${ }_{1028}$ viding recommendations specific to a problem domain 1029 such as IT service support. Therefore, a specialized 1030 
18 R. Valverde et al. / ITLL-based IT service support process reengineering

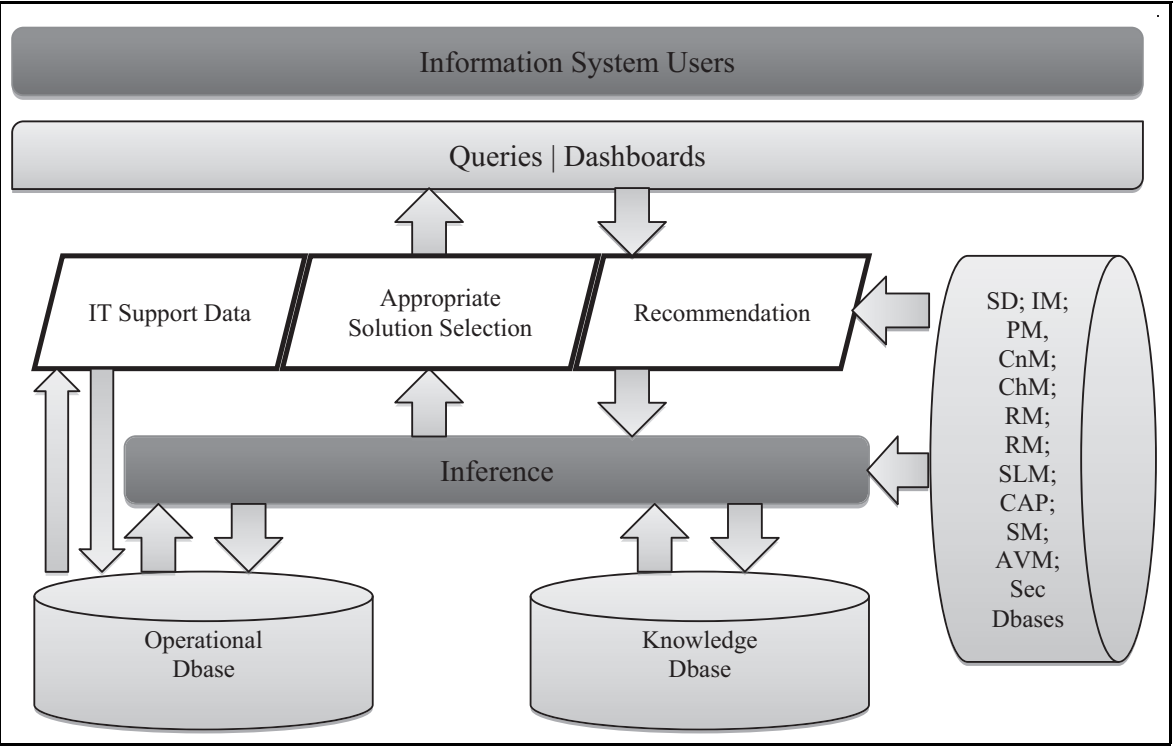

Fig. 17. Architecture of a decision support recommendation system. (Colours are visible in the online version of the article; http://dx.doi.org/ 10.3233/IDT-130182)

DSS such as a recommendation system would entail the manipulation of multiple attributes with a proper combination of data structure and scientific methodology vital to achieve its goal successfully. In effect, the recommendation system takes the form of a typical DSS with database, knowledge-base and inference components. Figure 17 shows the architecture of a decision support recommendation system, which includes: the DSRS interface with query interaction capabilities and dashboards; the inference engine for logic/algorithm computations; and the database composed of the knowledge and operational data.

Any collaborative filtering system such as the one used at the query and dashboard layer must rely on a substantial database of users' past actions (questions, incident reports, conflict resolution outcomes, ratings, etc.) in order to find the similarities and differences between them and a given user. In our proposed architecture this would translate into a database of users' portfolios. Using methods from recommendation systems body of knowledge, the process of using the CIRS would entail five primary steps as shown in Fig. 18.

1. In order to generate initial recommendations an assessment form of the current state of affairs need to be included. This form would include some logic to provide a score.

2. Based on the score obtained the system generates initial user support suggestions. This represents a filtering method, since in the beginning the users hold no portfolio of support requirements. The

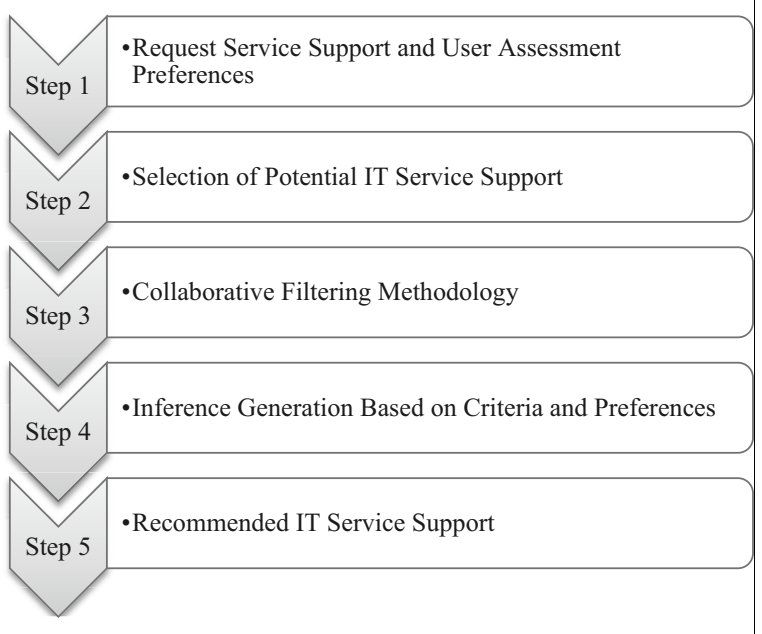

Fig. 18. Inference process for recommendation. (Colours are visible in the online version of the article; http://dx.doi.org/10.3233/ IDT-130182)

users are able to view available query and support ${ }_{1061}$ threads, thereby further filtering them according 1062 to various preferences and usage criteria.

3 . Once the information of a number of support services have been logged, the collaborative filtering mechanism starts making recommendations. 4. In doing so, it starts to form the neighborhood ${ }_{1067}$ of $n$ similarly user-problems sets with "similar" ${ }_{1068}$ service support requests. Similarity can then be 1069 calculated based on Jaccard index. The proce- 1070 dure further examines the portfolios of the user- ${ }_{1071}$ 
problems-solution sets in the same neighborhood and counts the frequencies of the support services.

5. Service support user-problem with the highest frequencies of occurrences is then presented to the service desk clerk/professional/user as recommendation to the request service support request.

The clerk/professional/user may choose among or make other selections from the ones not explicitly recommended to him/her.

A note on the Jaccard index is worth providing at this point. The Jaccard index (rooted in macroecology), is defined as the study of ecological patterns and processes at scales of space and time, beyond the reach of manipulative experiments. This methodological relies on observational or inferential hypothesis tests, a fundamental pattern is the way in which the total number of species of interest increases as the sampled area increases (Jaccard, 1901). The increase in number of species is due to the fact that as more individuals are sampled, the chance of encountering additional species increase and that a larger area is likely to be more environmentally heterogeneous, thus containing additional species that differ in their niches.

The Jaccard index (JI), also known as the Jaccard Similarity Coefficient (JSC), is a measurement that is used for identifying the degree of similarity and diversity of two data sets. This major trend in 'similarity' research has been applied in various contexts such as in the field of numerical taxonomy, and wherever individuals characterized by a number of attributes are compared. The comparison is viewed as a means to identify the degree of resemblance or dissimilarity between a particular pair of individuals.

\section{Conclusions, limitations and recommendations for future research}

Although the results of all KPIs examined in this case study have demonstrated some improvement, it did not fully meet our initial expectations, as some of the processes did not have significant improvement. There are two major possible explanations for this outcome pattern. Firstly, the duration of the test is not long enough for the test group to experience ample improvement. For example, there were no major SM upgrades performed during the test period. Secondly, some of the intended process reengineering efforts couldn't be fully implemented during the period of this case study, as it required more time, effort, and budget. For example, the Problem Management required a focus group and a pool of technical expertise that was not possible during the pilot project. However, a case study like this one serves as a trigger for major reengineering of business processes. It could motivate the senior management to allocate appropriate budget, and plan a gradual implementation of process reengineering. The ITIL framework consists of a well evaluated, explored and maintained set of guidelines. It certainly serves a tool for exploring process reengineering and improvements while meeting the budget constraints. The case study required a lot of coordination and consensus while identifying process improvements, establishing a process reengineering methodology, and constructing questionnaires for process evaluation. The experience gained in a case study like this one can alleviate the possibility of expensive mistakes if a major process reengineering is initiated at once. Actually, the customer company appreciated the efforts in this case study, well received, and motivated for further reengineering of companywide processes. The chapter also proposed a comprehensive DSS client/server system which further improves the IT service support process in reading real time KPIs and IT service actions. Further work to this research can focus on automatic implementation of IT service support actions based on DSS signals.

One limitation of this study is its lack of generalizability since it involved only one set of data. Many critics question the academic value of the case study method as they argue that the finding or results can not be generalized [4]. However, [3] insists that "the reliability of a case study is more important than its generalizability" since it presented an evidence and the findings can be very useful in fixing a hidden problem and improving the overall business process. [3] states that if case studies are: carried out systematically and critically, if they are aimed at the improvement of the field of study, if they are relatable, and if by publication of the findings they extend the boundaries of existing knowledge, then they are valid forms of research [3]. The limitations of this case study include the sample size since we are using convenience sampling and this can compromise the accuracy of the results. Another limitation could be the bias of research team since the same person or team is involved in data collection, analysis and benchmarking of the ITIL application [22].

\section{References}

[1] A. Caster-Steel and W. Tan, Implementation of IT infrastruc- 1168 ture library (ITL) in Australia: Progress and success fac- 
tors, 2005 IT Governance International Conference, Auckland, New Zealand, (14-15 November 2005).

[2] CCTA, (The UK central computer and telecommunications agency), Information Technology Infrastructure Library, HSMO Books, London, UK, 2011.

[3] M. Bassey, Pedagogic research: On the relative merits of search for generalization and study of single events, Oxford Review of Education 7(1) (1981), 73-79.

[4] J. Bell, Doing your research project, Milton keynes: Open University Press, 1992.

[5] I. Benbasat, D. Goldstein and M. Mead, The case research strategy in studies of information systems, MIS Quarterly 4 (1987), 368-386

[6] M. Brenner, I. Radistic and M. Schollmeyer, A case-driven methodology for applying the MNM service model, Proceedings of the 8th International IFIP/IEEE Network Operations and Management Symposium (2002).

[7] M. Brenner, Classifying ITIL processes, A taxonomy under tool support aspects, IEEE/IFIP International Workshop on Business-Driven IT Management (2006), 19-28.

[8] N. Denzin, The research act, Englewood cliffs, NJ: Prentice Hall, 1984 IT governance institute 2000 , COBIT $3^{\text {rd }}$ edition network, TM, London, 1984.

[9] C. Despont-Gros, H. Mueller and C. Lovis, Evaluating user interactions with clinical information systems: A model based on human-computer interaction models, Journal of Biomedical Informatics 38 (2005), 244-255.

[10] D. Grigori, F. Casati, M. Castellanos, U. Dayal, M. Sayal and M.-C. Shan, Business process intelligence, www. sciencedirect.com, science@direct, Computers In Industry 53 (2004), 321-343.

[11] H. Xin, IT service support process meta-modeling based on ITIL, International Conference on Data Storage and Data Engineering (DSDE) (2010), 127-131.

[12] M. Jantti, Improving incident management processes in two it service provider companies, $22^{\text {nd }}$, International Workshop on Database and Expert Systems Applications (DEXA), (2011), 26-30.

[13] A. Lahtela, M. Jantti and J. Kaukola, Implementing an ITILbased IT service management measurement system, International Conference on Digital Society (ICDS) (2010), 249-254.

14] T. Lucio-Nieto and R. Colomo-Palacios, ITIL and the creation of a service management office (SMO): A new challenge for IT professionals: An exploratory study of Latin American companies, $7^{\text {th }}$ Iberian Conference on Information Systems and Technologies (CISTI) (2012), 1-6.

[15] L.W. Neuman, Social Research Methods: Qualitative and Quantitative Approaches, $3^{\text {rd }}$ edition, Boston: Allyn and Bacon 1997.

[16] F. Niessink and H.V. Vliet, The Vrije Universiteit IT Service
Capability Maturity Model, Technical Report IR-463, Release L2-1.0. Vrije Universiteit Amsterdam, (1999).

[17] W. Orlikowski and J. Baroudi, Studying information technology in organizations: Research approaches and assumptions, Information Systems Research (1991).

[18] R. Pereira and M. Mira da Silva, A maturity model for implementing ITIL V3 in practice, $15^{\text {th }}$ IEEE International Enterprise Distributed Object Computing Conference Workshops (EDOCW), (2011), 259-268.

[19] B. Phifer, Next-generation process integration: CMMI and ITIL do devops, Cutter IT Journal 24(8) (2011), 28-33.

[20] V. Sekaran, Research methods for business: A skill building approach, John Wiley, New York, 1992.

[21] B. Sommer and R. Sommer, A Practical Guide to Behavioral Research: Tools and Techniques, $4^{\text {th }}$ edition, New York: Oxford University Press, 1997.

[22] S. Soy, The Case Study as A Research Method, available on the internet (www.gslis.utexas.edu/ ssoy/usesusers/ 1391d1b.htm) (15 March 2003), (1996).

[23] M. Spremic, Z. Zmirak and K. Kraljevic, IT and business process performance management: Case study of ITIL implementation in finance service industry, $30^{\text {th }}$ International conference on Information Technology Interfaces (ITI), (2008), 243-250.

[24] R.E. Stake, The Art Of Case Study Research, California: Sage, (1995).

[25] S. Ku, Y.-H. Suh and G. Tecuci, Building an intelligent business process reengineering system: A case-based approach, Intelligent Systems in Accounting, Finance, and Manageent $\mathbf{5}$ (1996), 25-39.

[26] W.M.P. van der Aalst and A.J.M.M. Weijters, Process mining: A research agenda, www.sciencedirect.com,science@direct, Computers In Industry 53 (2004), 231-244.

[27] W.M.P. van der Aalst, Business Process Simulation for Operational Decision Support, BPM 2007 workshops, LNCS 4928, (2008), 66-77.

[28] R.K. Yin, Case study research-design and methods, in: Applied Social Research Methods Series 5 2nd ed., Newbury Park: Sage, (1994)

[29] Z. Michael, The role of DSS technology in knowledge management, The IFIP TC8/WG8.3 International Conference (2004), 861-871.

[30] W.G. Zikmund, Business research methods, 6th edition, The Dryden Press Forth Worth,2000.

[31] M. Salle, IT service management and IT governance: Review, Comparative Analysis and their Impact on Utility Computing, HP Laboratories Paolo Alto, HPL-2004-98 (2004), 16-17.

[32] D. Pultorak, C. Henry and P. Leenards, Microsoft operations framework 4.0 (MOF 4.0), 2008, Van Haren Publishing, ISBN 9789087532864 , (September 2008), 8-20. 